\title{
INVESTIGACIONES
}

de HISTORIA ECONÓMICA

IHE. Primavera 2009. Pp. 11-38

\section{Teorías del valor y la función empresarial}

\section{The theories of value and of the entrepreneurial function}

\author{
ESTRELLA TRINCADO AZNAR \\ Universidad Complutense de Madrid
}

\begin{abstract}
RESUMEN
En este artículo se estudian las teorías del valor, del crecimiento y del empresario de tres importantes autores, David Hume, Adam Smith y Jeremy Bentham. Se demuestra que el utilitarismo y las distintas teorías del tiempo son la base de las diferencias de estas concepciones, que incluso tienen distintos "protagonistas". Los tres autores son innovadores en teoría económica y sus obras pueden considerarse paradigmas de tres distintos modelos económicos.

PALABRAS CLAVE: Teorías del Valor, Teoría del Empresario, Crecimiento Económico, Utilitarismo

Códigos JEL: B11, B12, B41, 010

\section{ABSTRACT}

This article studies the theories of value, economic growth and entrepreneurship of three relevant authors, David Hume, Adam Smith and Jeremy Bentham. Utilitarianism and their different conceptions of time are the basis for different theories, which are even represented by different main characters. The three economic theories are original and theoretically innovative and we may use them as three different economic models.

KEY WORDS: Theory of Value,

Entrepreneurship, Economic Growth,

Utilitarianism

JEL Codes: B11, B12, B41, 010
\end{abstract}




\section{Introducción ${ }^{1}$}

7 radicionalmente, se ha considerado la teoría de la utilidad como un fundamento de la economía, es decir, la economía describe la acción humana como una reacción a una imagen de placer-dolor futuro (siendo el placer atractivo y el dolor repulsivo) $)^{2}$. Sin embargo, cada vez es más claro que algunos grandes maestros y primeros economistas, que a la postre fueron los que establecieron las bases de la ciencia, eran críticos de las teorías de la utilidad defendidas en su tiempo ${ }^{3}$.

La teoría de la utilidad se basa en una determinada concepción del tiempo. De hecho, en el estudio de las distintas visiones de la economía - y la moral - la percepción del tiempo parece constituir el principal factor diferenciador. En las ciencias sociales, el tiempo ha sido a menudo considerado la base de la clasificación entre continuismo-discontinuismo ${ }^{4}$. Pero la retórica del continuismo es distinta en distintos autores. De hecho, en base a las teorías del tiempo, podemos diferenciar tres tipos de "teóricos" continuistas en economía ${ }^{5}$. Son los utilitaristas conservadores (teóricos de la imagen del pasado), los utilitaristas progresistas (teóricos de la imagen del futuro) y los "no utilitaristas" (teóricos del presente) ${ }^{6}$. La Historia del pensamiento económico nos permite poner un ejemplo paradigmático de cada uno de estos "teóricos": David Hume (1711-1776) podría definirse como utilitarista conservador, Jeremy Bentham (1748-1832) como utilitarista progresista y Adam Smith (1723-1790) como "no utilitarista" ${ }^{\prime 7}$. La elección de estos tres autores de gran envergadura para

[Fecha de recepción del original, agosto de 2007. Versión definitiva, julio de 2008].

$1 \quad$ Universidad Complutense de Madrid, estrinaz@ccee.ucm.es. Agradezco a Carlos Rodríguez Braun y a Manuel Santos su ayuda e ideas, así como la financiación del proyecto del MCyT 2004-07. Partes del artículo se han presentado en distintos congresos: 2008: Praga; 2006: Londres; 2005: Lisboa, Stirling, Nueva York y Cambridge; 2004: Treviso; y 2002: Creta.

2 Cabrillo (1991), p. 13, confirma que la mayor parte de los economistas están influidos de una u otra forma por los principios de la escuela utilitarista.

3 Roncaglia (1997), p. 319, dejó deslizar la siguiente empresa: “en mi opinión, queda por desarrollar el tema de la comparación entre las diferentes visiones del agente económico: el Smithiano, o el de la Ilustración escocesa, y el utilitarista... no sólo la teoría moral de Smith fue eclipsada, sino también un debate de larga tradición que surge especialmente en el siglo XVIII en relación a las pasiones e intereses humanos que dibujaba a hombres intrínsecamente sociales, multidimensionales y complejos".

4 El discontinuismo parte y llega al "vacío" social o psicológico -de manera constante (e.g. el anarquismo) o previsible y repentina (e.g. el marxismo)-, el continuismo parte de una existencia previa.

5 Ver Trincado (2003a, y 2006).

6 Como vemos, esta clasificación sigue la flecha del tiempo: pasado-presente-futuro. Los sistemas basados en la utilidad son finalistas: en el caso conservador, este finalismo se basa en la supervivencia, en el progresista en la imagen de las consecuencias de las acciones sobre el placer.

7 Haakonssen (1981), p. 167 y Vivenza (2001), pp. 97-104, tacharon injustamente a Smith de "utilitarista contemplativo" (ver Ross (1995), p. 167). La descripción de Griswold (1999), p. 540, es más ajustada. 
representar cada una de las teorías no es casual. Las tres son teorías puras del ser, no del deber ser, de modo que buscan el porqué de la actuación del hombre. Además, las tres constituyen un gran "sistema" filosófico-moral, legal y económico. Las tres son fundamento de la economía actual y, hay que decir, la mayoría de los demás autores continuistas podrían considerarse clasificados en cualquiera de las tres bases filosóficas.

En este artículo veremos como esas distintas concepciones de la utilidad, y por ende del tiempo, hacen que las teorías económicas de Hume, Smith y Bentham diverjan sustancialmente. En particular, nos centraremos en la diferencia que esas concepciones marcan en una noción fundamental de la economía: la teoría del valor. Comprobaremos que Smith sienta las bases que luego critica Bentham, aunque ya Hume había presentado una teoría híbrida entre ambos. Además, el elemento que, según los distintos autores, da valor a los bienes económicos determina la función del agente económico, sea consumidor, empresario, trabajador... Para centrar la atención en una función económica fundamental que da valor a los bienes económicos trataremos aquí la figura del empresario, pasando del hombre activo de Hume, al empresario prudente de Smith para acabar con el hombre de talento de Bentham.

De hecho, en general, podemos decir que los tres autores ponen en acción distintos tipos de "protagonistas". La acción humana basada en el presente - la Smithiana - se guía por motivos que surgen de lo íntimo del hombre y que no requieren de construcciones artificiales ni de imágenes - la curiosidad, la creación o el juego e, incluso, la indignación. Sin embargo, la acción humana basada en el pasado - Hume - o en el futuro - Bentham - buscan una imagen epidérmica y cambiante- el hábito de lo ya vivido, el placer imaginado... Podríamos definir al protagonista de la teoría económica de Smith como el "hombre ético" de Kierkegaard; los de Bentham y Hume son los "hombres estéticos", según la terminología del mismo Filósofo ${ }^{8}$. El hombre ético asume deberes de toda la vida, que no admiten excepciones ${ }^{9}$. Sin embargo, la única meta del "hombre estético" es la propia satisfacción. Evita el dolor y el hastío, vuela siempre hacia nuevas satisfacciones, dejándose llevar por la pasión del momento y huyendo de la responsabilidad con el pasado. Por eso, según Kierkegaard, lo estético es un estado de permanente insatisfacción, de un viajar con esperanza para "no" llegar".

$8 \quad$ Kierdegaard (1965).

9 Lo ético aparece para Kierkegaard como el reino de la tranquila satisfacción en la obligación cumplida. Es el hombre prudente de Smith, que no valora las cosas por su capricho, sino por lo que "de verdad valen", es decir, por lo que cuestan a la sociedad.

10 El de Bentham es este hombre huidizo, que busca auto-complacerse y valora las cosas caprichosamente. El de Hume, sin embargo, es un hombre que busca actividades que le hagan olvidar su estado melancólico. 


\section{Teorías del valor}

\subsection{Diferentes teorías del valor}

"El estado progresivo es realmente alegre y animoso para todas las clases de la sociedad. El estacionario es desvaído; el regresivo, melancólico"11. En esta conocida cita de Adam Smith, el autor contrapone la alegría a la melancolía, es decir, la curiosidad hacia el futuro al apego al recuerdo. De hecho, puede que la noción de curiosidad natural, presente en varias de las obras de Smith, determinara un cambio fundamental en sus ideas ${ }^{12}$. Smith en sus primeras Lecciones de Jurisprudencia habla de una abundancia que debe "fomentar" el Estado, mientras que en la Riqueza de las Naciones pasa a la idea de crecimiento económico, que debe "permitir" el Estado ${ }^{13}$. Para Smith, frente a lo que defendieron Hume y Bentham, la consecuencia positiva de la generación de riqueza no es que incremente la cantidad de "felicidades" - la utilidad futura - a que da acceso el dinero, sino el mismo hecho de la posibilidad de "romper" el hábito disfrutando del sentimiento de curiosidad y creación, sentimientos típicamente presentistas.

El sentimiento de "alegría" que se disfruta con el crecimiento económico es en Smith una creación y curiosidad hacia la imagen que se constata en "El impulso natural de cada individuo a mejorar su propia condición", el medio que el hombre normal usa para salir del estado de "pasividad" de las pasiones ${ }^{14}$. Este impulso no busca la satisfacción del placer, sino que el hombre, a través de él, intenta convertirse en centro de atención por sus riquezas, como Smith plantea en la Teoría de los Sentimientos Morales $^{15}$. Algo no necesariamente digno de alabanza, pero que es consecuencia de la necesidad psicológica de romper la habituación ${ }^{16}$. Es lo que lleva a que los trabajadores tengan ambición y estímulo al trabajo cuanto más alto sea el salario $^{17}$. Esta ilusión es, de hecho, lo que nos permite sentir una continuidad temporal ${ }^{18}$.

$11 \quad$ Smith (1994), p. 129.

12 Smith (1976), p. 630: WN: IV: VII: a: 14; Smith (1980), p. 48; o Smith (1997), p. 52.

13 En adelante, citaremos Lecciones de Jurisprudencia como LJ (A), si son las lecciones de 1762-3 y LJ (B) si son las de 1766. La Riqueza de las Naciones se citará RN en su versión reducida traducida por Alianza, y WN en la original.

14 Smith (1994), p. 438, 440, 444; Smith (1976), p. 582, WN: IV: V.

15 La Teoría de los Sentimientos Morales se citará TSM en adelante. Lo que Smith dice es “Lo que nos interesa es la vanidad, no el sosiego o el placer. Pero la vanidad siempre se funda en la creencia de que somos objeto de atención y aprobación." Smith (1997), p. 124. Sin embargo, en Smith (1997), pp. 395-409, dice que queremos mejorar nuestra condición por el mantenimiento de un status social.

16 "El medio a través del cual la mayoría de la gente aspira a mejorar su condición es el aumento de su fortuna. Se trata de una fórmula vulgar y evidente..." Smith (1997), p. 438.

17 Marshall (1998).

18 La búsqueda engañosa de una felicidad distante no reporta felicidad real, sólo concepción del tiempo. En la TSM, Smith demuestra que el hombre que dedica toda su vida a intentar "ascender", incluso con engaños, 
Es decir, la acción económica no busca la utilidad, si no una concepción del tiempo, y los bienes que producimos con ese trabajo no tienen valor por su utilidad. De hecho, si el trabajo no estuviera dividido, los bienes "no" tendrían valor. Para Smith, los bienes no tienen valor intrínseco individual, más allá del mercado.

\subsection{La paradoja del agua y los diamantes de Adam Smith}

Como es sabido, Smith volvió a la paradoja del agua y los diamantes para demostrar que no puede considerarse el valor de los bienes directamente dependiente de su utilidad. Esto no debe explicarse por la incapacidad de Smith de apreciar la escasez relativa del diamante frente al agua, que lleva a que la utilidad marginal del bien sea inferior en el segundo caso que en el primero. Smith rechazó de manera consciente la teoría del valor subjetiva que había heredado, de la que disponía en los trabajos de su maestro Hutcheson. La concepción del valor como dependiente de la utilidad y la escasez relativa la había postulado Smith en sus Lectures ${ }^{19}$. Sin embargo, en la RN Smith expone una teoría "coste de producción" del valor y relegó todo el material proveniente de autores precedentes a la discusión de las fluctuaciones del mercado a corto plazo.

La razón para el rechazo de Smith a la teoría del valor utilidad era más profunda de lo que se suele afirmar ${ }^{20}$. Intentaba reforzar su alejamiento de la doctrina de la utilidad y de la acción humana basada en la búsqueda de un placer de la imaginación ${ }^{21}$. Efectivamente, dice Smith, cuando decimos que un hombre ha descubierto cuánto vale realmente una cosa estamos hablando de un valor objetivo... ha descubierto cuánto cuesta producir o mantener ese objeto, ha hilado por vez primera unas relaciones de ideas que le llevarán a "darse cuenta" de un realidad, de qué significan cada uno de los minutos de trabajo y experiencia que requiere producir esa cosa. No es, por tanto, el valor subjetivo de la utilidad individual lo que genera valor, sino lo que cuesta producir el bien a la persona a la que se lo compramos ${ }^{22}$. El disfrute dife-

finalmente se encuentra que ha perdido la vida por la imagen. Argumentos parecidos llevarían a John Stuart Mill a afirmar que el estado estacionario podía ser un ideal sin competencia económica, Mill (1978), Libro IV, cap. 6. Sin embargo, para Smith, en las condiciones psicológicas actuales, sólo el crecimiento saca al hombre del estado de subsistencia.

19 Smith (1978), p. 487, LJ (B): 205-6 y Smith (1978), p. 488, LJ (B): 209.

20 Ver O’Brien (1989), pp. 115 - 116.

21 El utilitarismo ha calado tanto en la teoría económica que muchos han considerado que Smith estaba creando un confusionismo alrededor de la "verdadera" teoría del valor, basada en la utilidad subjetiva (ver Blaug, (1959), pp. 150-3; y Hutchison (1976), pp. 481-92).

22 Es reveladora la idea de Young (1995) que relaciona la teoría jurisprudencial de Smith con su visión del valor-coste de producción, y afirma que el concepto de coste de producción incluye uno de daño. 
rencial de los bienes depende de una función del orgullo de poseerlos, comparativa a la sociedad, o del capricho. Este capricho se puede medir a través del precio a corto plazo $^{23}$.

En esta diferenciación entre precio a corto y precio de coste a largo plazo, como es sabido, Smith no era original, dado que Cantillon ya había diferenciado entre valor intrínseco y precio de mercado ${ }^{24}$. Pero una concepción basada en la utilidad afirmaría que el valor intrínseco del bien podría ser el elemento interno de su derecho de propiedad ${ }^{25}$. Éste consistiría en una relación subjetiva de placer reportado por el bien al hombre, que podría idealmente sustraerse de la sociedad. Sin embargo, Smith no concibe el elemento interno como una relación de placer con la cosa, ni de dolor respecto a la producción de la cosa, sino que la valora en términos del sacrificio que el comprador se evita e impone a otros lo que, de hecho, implica externalidad ${ }^{26}$. Para Smith el valor natural de largo plazo "también" se remite al mercado y a la escasez relativa ${ }^{27}$. Por tanto, vemos que la idea de espectador no es para Smith importante sólo en su teoría ética (por su idea del espectador imparcial, presentada en la TSM), sino también en la economía ${ }^{28}$. Eso no quiere decir, como apunta Fleischacker, que la teoría del valor de Smith deba relacionarse con una discusión moral ${ }^{29}$. El precio real no está referido a hechos morales; Smith lo utiliza porque es indispensable para comparar el nivel de vida de las naciones y periodos históricos.

En la carta del Gobernador Pownall a Smith, éste le critica diciendo que, antes de que un hombre tenga una propensión a intercambiar, debe tener una utilidad prevista que se logra "en el deseo recíproco, la necesidad de una interrelación de ofertas mutuas" 30 . Pero Smith no respondió ni cambió su teoría. Lo que él intentaba demostrar era que, en el intercambio, el hombre no busca una imagen del placer que

Sin embargo, Winch dice que Smith no "quiso" retrasar el progreso de la teoría de los precios de mercado basada en la utilidad subjetiva de los consumidores, aunque sí el de una teoría de los precios donde todos los valores se derivan de los deseos individuales de los compradores, ver Kauder (1953).

Cantillon (1950). Esta idea de valor intrínseco podría ser el primer intento de basar el precio en alguna medida de los costes reales, Ekelund y Hébert (1992), p. 83.

25 Los elementos constitutivos del derecho real de propiedad son dos: a) El poder del sujeto sobre la cosa b) La relación del sujeto con los terceros. El primero es el elemento interno, la inmediatividad, el contenido económico del derecho real; el segundo es el elemento externo o formal, la absolutividad, la garantía jurídica de aquel contenido económico, ver Castán (1987), p. 40. Como dice Levy (1999), Smith empieza su estudio económico suponiendo dos individuos que comercian, no un Robinson, con lo que inmediatamente tenemos acceso al juicio del espectador.

$27 \quad$ Ver Fleischacker (2004), p. 125.

28 Ricardo tenía una idea semejante, al intentar estudiar los precios relativos. Sin embargo, la teoría del valor trabajo incorporado - en horas - impide, como veremos, remitir la idea de valor al mercado.

29 Fleischacker (2004), pp. 124-131.

$30 \quad$ Pownall (1776), p 338. 
le reportará su relación con el bien, creada con anterioridad a la transacción. El resultado de la distribución última de los bienes no es más que una "consecuencia no querida" del deseo del hombre de persuadir, de la propensión innata a intercambiar, algo que no necesariamente crea placer, aunque tal vez sí ilusión. En este caso, el efecto sorpresa, curiosidad y cambio ilusiona la mente del consumidor ${ }^{31}$.

Por tanto, para Smith, la cadena causa - efecto es de producción a consumo y no a la inversa. La crítica a la teoría del valor Smithiana que luego desarrolló Menger, demuestra lo incomprendida que fue la teoría de Smith ${ }^{32}$. Según Smith, no es que un diamante sea caro porque lo deseamos, sino que lo deseamos porque es caro y costoso, o porque es un medio barato para obtener bienes caros y costosos. La escasez lo que provoca es belleza debida a la exclusividad, a la ostentación y a la sensación de tener "poder" de comprar o de ordenar trabajo ${ }^{33}$.

\subsection{El precio natural de Adam Smith}

Smith presenta una teoría en que reaparece una especie de Bon Prix de los bienes primarios - también en sus LJ-, donde los precios y el mercado de estos bienes surgen sólo cuando son suficientemente altos para que merezca la pena aplicarse a la producción sistemática. Sólo serán altos cuando la escasez haga apetecible poseer ese bien, con un "precio ostensible"34. Mientras los bienes no alcancen ese precio suficiente, serán libres y no tendrán un administrador diligente que quiera conservar sus ingresos. Esto llevará a que el bien se derroche y se llegue, en última instancia, a esa escasez necesaria para alcanzar el precio que haga rentable su producción sistemática ${ }^{35}$.

Es decir, los bienes que se producen no son anticipados por los consumidores, pero se hacen necesarios para dar ingresos a los productores ${ }^{36}$. Una vez establecida la producción, dice Smith, los precios de mercado gravitarán en torno al precio

31 Dice Smith respecto a las producciones americanas que Colón llevó ante los reyes españoles para convencerles de la grandeza de su descubrimiento que "La única parte valiosa de aquellas consistía en algunos prendedores, brazaletes y otros ornamentos de oro y algunos paquetes de algodón. El resto eran meros objetos de admiración y curiosidad", Smith (1976), p. 603: WN, IV: VII: a: 14.

32 Menger pretendía devolver al diamante una utilidad ex ante al intercambio dado que, según él, el alto precio del diamante saciaba una "necesidad más urgente" que la última unidad de otro bien más abundante. Smith (1994), pp. 246-7. Así lo dirá luego Veblen.

34 "Se dice que los impuestos sobre los licores previenen el alcoholismo, pero probablemente el caso es el contrario. Incrementado el precio se hacen un objeto de deseo... La buena camaradería obliga a presionar a beber vino, que te vale todo lo que puedes costearte". Smith (1978), p. 363, LJ (A): vi: 86.

35 Smith (1994), pp. 303-15.

36 Efectivamente, la teoría austríaca es contraria a la de Smith. 
natural. De modo que la demanda efectiva - la de aquellos que están dispuestos a pagar el precio natural o precio de coste a largo plazo - dirigirá la oferta. Sin embargo, esta demanda lleva ya incluidos tanto la idea de coste como la de los factores institucionales necesarios para crear el valor ${ }^{37}$. No es el deseo de poseer bienes lo que afecta al precio, sino la posibilidad de costeárselos unida al deseo de estar orgulloso de ser capaz de costeárselos. Para Smith, la exclusividad es fundamental en cualquier objeto, incluso artístico, y cualquier imitación tiene menos mérito que el modelo ${ }^{38}$.

\subsection{El trabajo ordenado de Adam Smith}

Una concepción utilitaria y objetiva del valor intentaría reducirlo todo al trabajo incorporado en horas o energía, una forma de dolor que debemos minimizar. Sin embargo, en la RN, Smith recurre al "trabajo ordenado" o exigido como medida del valor. La teoría de Smith de trabajo ordenado no es, como en el caso de Locke, una continuación de su teoría jurídica del derecho de propiedad, en que la justicia exige que a cada uno se le pague según su trabajo. Como dice Smith, esta medida del trabajo exigido es una noción abstracta, no natural ni obvia. La idea de trabajo exigido en otros hace fundamental convencer a otra persona de que el bien que uno ha creado merece ser intercambiado por las horas y esfuerzo del que ha producido el otro. En ese sentido, incorpora la demanda como una condición previa del valor.

Ricardo creyó que Smith había incurrido en una confusión entre el trabajo incorporado y el ordenado ${ }^{39}$. Pero fue precisamente el absurdo de la teoría de valor trabajo incorporado ricardiana lo que llevó a la revolución marginalista. Jevons intentó confirmar de forma muy sencilla que el valor no depende del trabajo incorporado. Hay muchas cosas, como los libros antiguos, monedas y antigüedades raras, etc, que

37 De hecho, el incremento de la demanda, al estimular la competencia, profundiza la división del trabajo, con lo que hace que se reduzca el precio de los bienes a largo plazo, ver Smith (1994), p. 697. En este sentido, como dice Urrutia (1983), p. 19, para Smith la cantidad vendida se determina ex post al precio (es el precio del bien el que determina su demanda, no a la inversa).

38 Smith (1985). Dice Smith "los grandes propietarios... Por un par de hebillas de diamantes, o por otra cosa tan frívola e inútil, eran capaces de intercambiar la manutención... Pero esas hebillas serían de su uso exclusivo... Y así, para satisfacer la más pueril, despreciable y sórdida de todas las vanidades, enajenaron gradualmente todo su poder y autoridad" (Smith (1994), pp. 525-6; la cursiva es mía).

39 Sin embargo, Henderson (1954) y Das Gupta (1960) aclaran que Smith ha sido malinterpretado. La diferencia entre trabajo ordenado e incorporado "no" puede ser una confusión de Smith. Finalmente Ricardo acabó insatisfecho con su propia teoría del valor. Ver Ricardo a Malthus, 3 agosto 1823 y 15 agosto 1823, Ricardo (1966). 
tienen valores altos, y que no son en absoluto susceptibles de producción actual a través de trabajo. Por tanto, según Jevons, el trabajo incorporado no afecta al valor, sólo la utilidad ${ }^{40}$. Pero, hemos de decir, el caso que presenta Jevons no refuta, si no que confirma, la teoría de Smith. En las antigüedades raras, es obvia la idea de exclusividad pero su utilidad es bastante oscura. Efectivamente, dice Smith, el valor depende del trabajo, pero no, como malinterpretó Ricardo, del trabajo incorporado en el momento de la creación del bien, algo ya olvidado, sino el trabajo que el bien puede exigir de otros en el presente, que constituye, no su valor de uso, sino su valor de cambio. ¿Es eso, por tanto, la utilidad del bien? No una utilidad subjetiva, según Smith, sino una escasez relativa unida a la persuasión de los vendedores dentro de un mercado. Siempre, lógicamente, "en relación a" los demás bienes ${ }^{41}$. Al equilibrio se llegará tras un proceso de ajuste de mercado, interrelacionando la cantidad de bienes y factores en un modelo de equilibrio general ${ }^{42}$.

Pero, ¿en qué consiste ese trabajo ordenado? Smith comenta que, antes de la acumulación del capital y propiedad de la tierra, el producto del trabajo constituía su recompensa natural - y éste obtendría diferenciales salariales en función de la dificultad, suciedad... Sin embargo, la RN va hilando las relaciones que permiten "darse cuenta" de la función necesaria del capitalista y el terrateniente para la productividad del trabajo en un estado con propiedad privada, algo que es fruto del tiempo y la experiencia y que, por tanto, no se observa a simple vista ${ }^{43}$. El capital se ve retribuido por el beneficio porque hay un valor que al hombre le cuesta mucho tener en cuenta: el del paso del tiempo unido al esfuerzo del ahorro ${ }^{44}$. De hecho, la acumulación producida gracias a la frugalidad incrementa la cantidad de trabajo necesario para la producción, no a la inversa ${ }^{45}$. Por último, la renta de la tierra y su privatización es, según Smith, la mejor forma de gestionar una renta de monopolio de un bien con producciones alternativas. El terrateniente busca alojar a trabajadores agrícolas

vivimos en un mundo con escasez y mortalidad. Esta idea ya estaba presente en Hume.

Algunos autores consideran que, con su teoría del valor, Smith intentaba mostrar un índice de bienestar. Dice O’Brien (1989), pp. 121-2, que, para ello, Smith tendría que haber señalado que los salarios reales per cápita se elevan con el crecimiento económico, pero Smith sostiene que el salario medido en cereales es constante a largo plazo.

43 La experiencia del "darse cuenta" en psicología consiste en la apertura de una claridad que nos acerca a la comprensión de las cosas. En muchos casos, esa capacidad de comprensión intuitiva se obstruye porque realmente "no nos queremos dar cuenta" (Trincado 2003a).

Incluso Ricardo y Mill intentaron mostrar que el trabajo - esfuerzo - es el único factor que posee productividad, siendo la renta de la tierra una transferencia de riqueza; y los beneficios el interés más un salario de dirección, otra forma de trabajo. Sin embargo, finalmente Ricardo aceptó el tiempo de espera como diferenciador de la retribución del capital.

Smith (1994), p. 433. 
que le proporcionen, al menos, la misma renta que pagan a sus vecinos - para lo cual, es cierto, no necesita mucho conocimiento ni "desvelos"46.

En última instancia, por tanto, la teoría global de Smith no busca un valor esfuerzo de producir el bien, sino un valor esfuerzo de adquirirlo ${ }^{47}$. Eso incorpora el tiempo y esfuerzo de establecer las instituciones, así como de llevar el bien al mercado, sin los cuales no existiría el valor. No basta con el esfuerzo físico del trabajador para producir un bien porque para que ese trabajo sea productivo, hemos de "darnos cuenta" de que ha sido necesario un marco jurídico subyacente. El hecho de que el trabajo Smithiano sea el "ordenado en otros" hace que éste se mida "idealmente" en términos del esfuerzo del entramado institucional para que el trabajo sea productivo $^{48}$.

\subsection{El valor tras el cálculo felicífico de Bentham}

"Adam Smith ha echado luz sobre mucho humo; pero hay casos también donde ha echado humo donde antes había luz"49. Ésta es la descripción que Bentham, gran defensor del utilitarismo en el siglo XIX, hace de la teoría del valor Smithiana, y en términos parecidos criticará, en el margen de Table of the Springs of Action, la idea de la propensión a intercambiar - ¿por qué no decir que los individuos maximizan su utilidad $^{50}$ ?

Stark incluye una antología de escritos de Bentham que llama "la psicología del hombre económico" (que luego sería usada por la escuela de utilidad marginal y con una definición de hombre aceptada por muchos economistas). Según Bentham, la felicidad es una "idea", la expectativa del futuro placer y dolor que influye en la acción interesada y esperada. En The True Alarm, Bentham define riqueza en base a dos elementos: debe haber un objeto sensible y el objeto debe ser materia de uso y deseo. En el capítulo 5 discute la noción de valor: "Todo valor se funda en la utilidad".

46 Smith (1994), p. 89. Como demuestra Harris (1983), pp. 254-5, la propiedad de tierras no proviene del impulso egoísta de poder y riquezas, sino de procesos sistémicos que seleccionan poblaciones más densas y productivas. Como la extracción de rentas se asocia evolutivamente a un incremento en la producción de alimentos, algunos antropólogos consideran el pago de rentas como indicador de excedente. Sin embargo, si los productores entregan sus productos es porque no disponen del poder para retenerlos: toda renta es un aspecto de la política y en cierto modo semeja a un impuesto.

$47 \quad$ Smith (1994), p. 64.

48 Aunque eso incluye el adiestramiento, para Smith, el hombre se especializa por el ambiente, con lo que contradice las teorías del capital humano, que aseguran que el hombre programa sus estudios.

Stark (1954), p. 80, The True Alarm.

Bonner (1995). 
Pero ¿qué es el placer o la utilidad para Bentham? Cualquier cosa que el yo "pida para sí" puede considerarse placer. Aquello que el yo rehúya, será considerado dolor. El acercamiento de placer-rehusión de dolor, según Bentham, explica las acciones altruistas -podemos sentir placer al sentirnos generosos - igual que las tradicionalmente llamadas "egoístas". Por tanto, la diferencia entre altruismo - egoísmo desaparece. La predominancia de la autoconsideración sobre otros impulsos - la búsqueda del interés propio entendida como egoísmo - es para Bentham una especie de axioma dado que a él subyace el concepto filosófico de necesaria referencia del hombre a su yo hedonístico. "Cualquier hombre activado con relación a cualquier cosa aparte del yo, es un idiota: sólo aquél cuya consideración se confina al yo, es sabio. Yo soy de los sabios"

En base a esa psicología, la sociedad que presenta Bentham es una reunión casual y atomística de hombres competidores. La vida social no es un fenómeno natural, sino que sólo es posible si la bestia humana es reprimida ${ }^{52}$. Su avaricia por las cosas placenteras es inmensa, mientras que el número de las cosas buenas es pequeño. El resultado es una lucha de egoísmos. Surge la antipatía, un deseo de ver a otros tan mal como nosotros ${ }^{53}$. Concluyendo, el individualismo de Bentham es tanto filosófico como metodológico e incluso normativo: el hombre debe ser egoísta, a riesgo de ser tonto.

El hombre, por tanto, busca maximizar una suma de placeres y minimizar una suma de dolores esperados. Pero ¿hay acciones impulsivas precedentes a ese cálculo, con magnitudes positivas - negativas? Para Bentham, incluso la pasión calcula, aunque de modo confuso y, además, la pasión no es un modo de acción habitual. "La proposición de que la pasión no calcula, no es verdad, como casi todas las proposiciones generales y oraculares... Todos los hombres calculan" 54 . Como dice Mitchell, Bentham no se distingue por ser utilitarista ${ }^{55}$. Varios filósofos ingleses desde Richard Cumberland en 1672 ya habían expuesto la doctrina de la utilidad. Lo que diferencia a Bentham de otros es su deseo de introducir el método exacto en las discusiones de utilidad.

Bentham apunta que la cuantificación de experiencias físicas puede perfeccionarse y producir números concretos sobre valoraciones mentales, siempre cambiantes y

51 Stark (1954), p. 426, The Psychology of Economic Man: VII.

52 Stark (1954), p. 431. Esta idea es contraria a la teoría de la simpatía de Smith (Trincado, 2003 b) o de Hume (Trincado, 2008).

53 "La inclinación en el seno del hombre para la antipatía hacia otros hombres es, bajo todas las circunstancias, desgraciadamente copiosa y activa. La gama ilimitada de los deseos humanos y el muy limitado número de objetos adaptados para satisfacerlos, inevitablemente lleva a un hombre a considerar a aquellos con los que está obligado a compartir esos objetos como rivales". Stark (1954), p. 430.

$54 \quad$ Stark (1954), p. 434.

$55 \quad$ Mitchell (1918), p. 4. 
endógenas $^{56}$. Y esas valoraciones se producen, de facto, siempre que se menciona un precio monetario. El dinero puede ser una medida de placer o dolor individual. Pero, incluso, esta medida puede estar sujeta a una "objetividad subjetiva". De hecho, el valor de la unidad monetaria es alto para los que tiene poco dinero y bajo para los que tienen mucho, con lo que podemos decir que el valor del dinero relativo sí es objetivo, y nos es dable hacer comparaciones interpersonales entre los hombres a los que idealmente se les podría medir el umbral de placer. Si ceteris paribus dos hombres de iguales circunstancias pierden la misma cantidad de dinero en relación a su riqueza, podemos suponer que pierden la misma cantidad de felicidad ${ }^{57}$.

\subsection{Bentham y la paradoja del agua y los diamantes}

Bentham diferencia, como Smith entre valor en uso y valor en cambio, pero, según Bentham, a propósito de esta distinción Adam Smith es criticable: el agua puede tener valor de cambio en algunas situaciones, mientras que los diamantes pueden tener sus usos ${ }^{58}$. Las ideas de Bentham están continuamente rozando la de la importancia del principio marginal. En Axioms, el lector encuentra una exposición clara de la idea de "mínimo sensible" de riqueza dentro de la "masa de placer producido" ${ }^{59}$. Es evidente la diferencia de la teoría de Bentham con la teoría dinámica de Smith, en que las transferencias no se miden por la "masa" de placer producido sino, precisamente, porque el crecimiento genera sensación de continuidad del tiempo. Pero, además, Bentham formula también la idea de utilidad marginal decreciente ${ }^{60}$. Casi llega a plantear el principio de equimarginalidad, aunque no logra definirlo con nitidez ${ }^{61}$. La teoría de Bentham está cercana a la posterior metodología mengeriana, no sólo por el subjetivismo, sino porque también Bentham distingue entre bienes de orden superior e inferior, de producción o de consumo, y se basa en la cercanía al uso como parámetro diferenciador ${ }^{62}$.

Sin embargo, para Bentham el trabajo es "sólo" un bien instrumental, no uno de orden inferior. Contra Hume, como veremos, para Bentham el trabajo consiste en un dolor al estilo de Jevons, que sólo puede compensarse con el placer monetario del

\footnotetext{
$56 \quad$ Lapidus y Sigot (2000).

57 Sin embargo, dice Bentham, hay bienes de valor esencial e invariable, como las necesidades relativas, y bienes de valor variable y caprichoso, como los lujos relativos, cuya comparación de utilidad interpersonal es más difícil.

Stark (1954), p. 19 y Stark (1952a), p. 108-9.

Stark (1952a), p. 118.

Stark (1954), p. 438; Stark (1952a), p. 108 y pp. 113-4. Ver también Bentham (1981), pp. 110-116.

Stark (1952a), pp. 114-5.

Stark (1954), pp. 448-9 y p. 84. Ver Trincado (2004).
} 
salario: "Aversión - no deseo - es la emoción, la única emoción - que el trabajo, tomado por sí mismo, puede producir... En tanto que el trabajo se tome en su sentido propio, el amor al trabajo es una contradicción en los términos" ${ }^{\prime \prime 63}$.

Todo ello, permite a Bentham defender un principio estatista: "Si es correcto que un hombre sea infeliz, no lo es porque su felicidad tiene menos derecho a ser considerada que la de otro hombre, sino porque es necesario para la mayor felicidad del mayor número que se sacrifique una porción de su felicidad"64. En base a ese principio, Bentham defenderá la conveniente tendencia hacia la igualdad, fundamentada en la idea de utilidad marginal decreciente de la riqueza y con un método cuasimatemático ${ }^{65}$.

Sin embargo, también hay otro principio que llevaría a Bentham a justificar el conservadurismo económico: el objetivo del legislador debe ser mantener la distribución de la propiedad de modo que no se interfiera en la masa total de expectativas porque el "principio de minimización de la decepción" y la incertidumbre llevan a la anulación de la felicidad que produciría la redistribución e, incluso, a la anulación de la existencia ${ }^{66}$. La teoría de Bentham es completamente estática y supone la riqueza "dada", una imagen a la que el paso del tiempo no le afecta. Para Bentham, la redistribución del Estado no tendría más efectos negativos que los efectos estáticos de la desilusión por la detracción de la propiedad, e incluso, una redistribución hacia los ricos, podría tener efectos positivos, si la medida enriquece a las personas que tienen tendencia a ahorrar ${ }^{67}$. Bentham no estaba pensando en una reducción del incentivo o un menor crecimiento debido a la imposición exterior de una jerarquía. El legislador es en su sistema aquél que provee placeres - y la misma existencia.

Es cierto que las ideas de Bentham no fueron muy tenidas en cuenta en su tiempo, excepto Defence of Usury ${ }^{68}$. Los clásicos estaban favorablemente dispuestos a las ideas utilitarias, pero no usaron el cálculo felicífico para explicar acciones económicas $^{69}$. Sin embargo, ninguno se hubiera opuesto al principio de la mayor felicidad del mayor número. Su sesgo no intervencionista no se basaba en una filosofía "libertaria"; el concepto utilitario de gobierno subyacía a todas sus propuestas políticas ${ }^{70}$.

Stark (1954), p. 428, The Psychology of Economic Man: IX.

Stark (1954), p. 439.

Posteriormente los marginalistas han criticado el igualitarismo de Bentham - aunque no la filosofía de fondo - porque, dice Edgeworth, las personas son desigualmente capaces de disfrutar del placer y soportar el dolor, ver Murphy (1984), p. 171.

Stark (1952a), pp. 364-5 y pp. 111-2.

Stark (1952a), pp. 196-8, Defence of Usury. Proscript.

Collison (1988).

En el periodo clásico hay otra tendencia distinta de la ricardiana, que es subjetivista, de Say y Lloyd, Malthus, Senior, Longfield. Ninguno, sin embargo, utilizó la filosofía utilitaria de Bentham "explícitamente". John Stuart Mill no malinterpreta la actitud de sus contemporáneos cuando escribe en 1848 que el laissezfaire debe ser la práctica general; y que todo desvío del mismo, si no se requiere para un mayor bien, es un mal. Mill (1978). 
Aunque tal vez "es en el sentido Humeano más que en el Benthamita que podemos etiquetar a la escuela clásica como utilitaria"71. Ya, con la revolución marginal, el concepto Benthamita del homo oeconomicus, así como el concepto utilitario de gobierno, ganaron la batalla en la ciencia económica ${ }^{72}$. Para proporcionar felicidad, los marginalistas admitirán normalmente más posibilidad de interferencia en el mecanismo de mercado que los clásicos ${ }^{73}$.

\subsection{El valor utilidad del trabajo de Hume}

“Euge! Belle! Querido Mr. Smith: estoy encantado con tu trabajo, y su lectura me ha llevado a un estado de gran ansiedad... Si estuvieras aquí, discutiría contigo algunos de tus principios. No puedo creer que la renta de la tierra sea parte del precio del producto, sino que creo que el precio se determina absolutamente con la cantidad y la demanda"74.

Así alababa Hume la obra recién publicada de su amigo. Sin embargo, en su propia alabanza, el autor desvelaba los disentimientos de fondo en lo que respecta a la teoría del valor (a pesar de ciertos parecidos). La diferencia de Hume con Bentham, sin embargo, se debe a una distinta descripción de la naturaleza utilitaria del hombre, y eso aún a pesar de que ambos basan su teoría del valor en la psicología y en la utilidad.

En la teoría de Hume, las pasiones son reducibles a un sentimiento y la simpatía e imaginación que permiten enlazar sentimientos es esencial para entender su teoría del valor ${ }^{75}$. La teoría psicológica de Hume muestra que las impresiones individuales, gracias al hábito, llegan a una idea de las "cosas" que observamos, e incluso a una idea de "identidad personal"76. Para Hume la belleza y el valor son meramente de una naturaleza relativa, y consisten en un sentimiento agradable producido por un objeto en una determinada mente según su estructura peculiar y

71 Robbins (1953), p. 178.

72 Black (1988). Jevons vuelve en 1871 al principio de la mayor felicidad y a la consideración del placer y dolor como motivo de la acción. Cita a Bentham y habla del "cálculo felicífico". Igualmente, Marshall, en sus primeras lecciones hizo estudios sobre Bentham y, según Keynes, nunca se desvió de las ideas utilitarias. Pero las usó con cuidado porque no consideraba que la solución a los problemas económicos consistiera en una aplicación del cálculo hedonístico. Keynes (1925), p. 7.

73 En cualquier caso, como dice Urrutia (1983), si el marginalismo deja un regusto de desencanto no es porque justifique la intervención del estado, sino porque en él se produce una ruptura de "seducción y verdad".

$74 \quad$ Smith (1977), p. 186, carta 150 de Hume a Smith, desde Edimburgo 1 Abril 1776.

75 Árdal (1966).

76 Hume (1964 a). 
constitución. Además, el sentimiento agradable se distingue del objeto, atomizándolo ${ }^{77}$. Por tanto, la acción humana se basa en una imagen del hábito, del pasado, y de la imitación.

Esto afecta a la economía. En Of Commerce, Hume enfatiza la importancia del hábito y la imitación en el desarrollo de la actividad económica. Al ser el tiempo una rápida sucesión de impresiones incomparables, el miedo a ese cambio lleva al hombre a optar en lo social por el darwinismo institucional, la supervivencia de las instituciones que se han mostrado aptas para sobrevivir. En segundo lugar, esto implica que la razón no afecta a las pasiones ${ }^{78}$. Eso no quiere decir que no haya racionalidad en el mundo económico, pero la racionalidad es un resultado no intencionado de la elección pasional, un proceso en el que surge el mismo yo ${ }^{79}$. En un mercado libre, el valor de los bienes está determinado por la oferta y la demanda subjetiva, pero el hombre no puede medir esa utilidad cardinalmente ni puede compararla y, por tanto, no tiene capacidad aditiva ${ }^{80}$.

Para Hume, el estado desapasionado es tan negativo que el hombre huye de él incluso a través de emociones dolorosas, melancólicas... ${ }^{81}$. Es en Of Refinement in the Arts donde presta mayor atención a las causas o fines del trabajo. Estos son tres: el placer, la acción, y la indolencia ${ }^{82}$. El comportamiento económico implica no sólo un deseo de gratificar deseos, sino un deseo de tener y buscar deseos, sin los cuales el hombre caería en la languidez. "La vida humana es una escena tan aburrida,... que cualquier cosa les divierte, y aunque sea con una pasión unida al dolor, les da en lo principal un placer sensible" 83 .

En realidad, la teoría del valor de Hume es una teoría híbrida del valor utilidad - sólo la oferta y la demanda afectan a los precios - pero, unida a su doctrina del comportamiento humano, más podríamos denominarla "de utilidad del trabajo". Si Hume consideraba que la vanidad de la búsqueda de placer deja un vacío en el hombre... "Te digo que, incluso en medio de tus placeres lujosos, eres infeliz", hay, sin embargo, un placer genuino, el trabajo ${ }^{84}$. Éste es un placer del orgullo, y los demás

Hume (1964c), p. 219, The Sceptic: XVIII. Sin embargo, Hume creía que existen placeres superiores, como diría luego Mill, que pueden imprimirse en el hombre a través de la educación y el hábito. Pero éstos tienen poca influencia en la acción si no afectan al gusto y sentimiento. Hume (1964c), p. 222. Con lo que la teoría de Hume es un revulsivo a las modernas teorías de elección racional, como plantea Sugden (1991), p. 752.

79 Diaye y Lapidus (2005), p. 107. Ver Garrett (1997).

80 Hume (1986).

81 Hume (1964c), p. 325, Of Interest: IV. Tiene parecido a Adam Smith, pero en este caso desde una visión utilitaria, aunque menos mecanicista que la de Bentham.

82 Hume (1964c), pp. 300-1, Of Refinement in the Arts: II.

83 Hume (1964b), p. 442, Dialogues: X.

84 Hume (1964c), p. 207, The Stoic subtitulado "The Man of Action and Virtue": XVI. 
placeres se ven como un premio al trabajo realizado. "Sabed que el trabajo es, en sí mismo, el principal ingrediente de la felicidad, a la que aspiramos, y que cada disfrute pronto se hace insípido y sin sabor cuando no se adquiere por la fatiga e industria" 85 .

Pero, a esto, debe añadirse como fin del trabajo la avaricia o deseo de ganancia que Hume interpreta de varios modos.

Primero, el motivo para acumular se asocia con la identificación del dinero con un sentimiento de poder que produce orgullo, que es, en definitiva, una creencia ${ }^{86}$. La pasión por la ganancia es un deseo de acumular símbolos de éxito y el avaro adquiere placer al observar el incremento diario de su fortuna ${ }^{87}$. En este sentido "La miseria de otro nos da una idea más viva de nuestra felicidad y su felicidad de nuestra miseria. La primera, por tanto, produce gozo, y la última, dolor" ${ }^{\prime \prime}$.

La segunda interpretación de la avaricia es como "causa de trabajo" y no está unida tampoco al deseo de placer, sino al deseo de acción, de emplearse lucrativamente. La riqueza es sólo un fin instrumental de la acción. Pero, con el tiempo, y aunque en principio no nos importara, adquirimos un interés por el fin en sí, como una imagen de la pasión, y nos sentimos defraudados cuando no logramos el propósito. A esto podríamos llamarlo "instinto adquisitivo".

En Of Interest vemos que el deseo de beneficio es opuesto a la pasión real por placeres, derivada del consumo de riqueza. Esta idea diferencia claramente la teoría de Hume de la de Bentham (la ética del placer sin esfuerzo). Para Hume, la actividad económica es intrínsecamente gratificante y los mayores obstáculos para satisfacer las necesidades frecuentemente generan una expansión del esfuerzo tan grande como para producir un incremento del nivel de vida mayor que los niveles preexistentes ${ }^{89}$.

En este sentido, Hume rompía con las ideas predominantes en su tiempo, cuando la mayoría de los escritores argumentaban que la masa de trabajadores estaba poco dispuesta hacia la actividad económica. Los mercantilistas consideraban la indulgencia al placer como el placer por la pereza, Hume lo considera como una frustración, el intento de compensar a través del placer el deseo de viveza que resulta de la inacción.

\footnotetext{
Hume (1964c), p. 206.

Davidson (1976).

Hume (1964b), p. 109, Treatise: “Of Property and Riches": II: I: X.

Hume (1964b), pp. 160-1, Treatise: “Of Malice and Envy": II: II: VIII.

Hume (1964c), p. 206.
} 


\subsection{Diferencias entre el valor de Hume y el de Smith}

Aunque la teoría del valor de Hume y la de Smith parecen, en algunos puntos, semejantes, son bastante diferentes. Vamos a plantear, por lo menos, cinco de estas diferencias como modo de aclarar sus teorías.

En primer lugar, el hombre tanto para Smith como para Hume juzga las consecuencias de la actividad económica - la riqueza - por comparación. Sin embargo, para Smith la causa de la actividad económica es el deseo de persuadir, esa propensión innata al intercambio. Hume considera que lo que lleva al hombre a trabajar es un deseo de estar activo para no caer en la languidez. En el caso de Hume no es necesaria, por tanto, la idea de alteridad en la causa de la actividad económica o del trabajo. La alteridad puede ser un motivo más para la acción dado que, como dijimos, el acumulador procede así porque la miseria de otro le da una idea de su propia felicidad y, además, la imitación produce crecimiento. Sin embargo, es importante distinguir entre las consecuencias de la acción - en ambos autores la misma, una belleza que se juzga por comparación social - con las causas últimas de la acción - en el caso de Smith el deseo de intercambiar, que implica alteridad, y en el de Hume el deseo de actuar, que no la implica. Por tanto, para Hume, ya no es necesario estudiar el entramado de relaciones sociales para definir la causa del valor económico.

En segundo lugar, aunque el hombre valore comparativamente la actividad económica, para Smith la imagen de la belleza es un capricho tan temporal que no afecta al valor de los bienes. Éstos se ven determinados objetivamente por lo que le cuesta a la sociedad producirlos. Sin embargo, para Hume, el valor de los bienes es subjetivo aunque no podamos sumar las subjetividades porque dependen de la constitución primitiva de la mente individual.

En tercer lugar, Smith pensaba que el trabajo "debe" ser un sacrificio, a riesgo de que la teoría se pervierta. Es el deseo de mejorar la condición propia lo que genera ilusión, no el trabajo. El hombre intercambia trabajos e impone a otros un sacrificio que él se ahorra. Sin embargo, para Hume, el trabajo es un placer, no un coste, con lo cual no hay un límite para las horas de trabajo, más allá de la capacidad de trabajar, que se logra complementando el trabajo con una conveniente indolencia. Esto pone en duda la teoría del salario de subsistencia - lo que afecta a la teoría del crecimiento de la población - y a la idea Smithiana de valor coste institucional de producir los bienes. Según Hume, el hombre necesita trabajar, no sólo para lograr la subsistencia y conveniencias de la vida, sino para introducirle en una actividad que le haga olvidar el sinsentido de la vida. Para Smith, sin embargo, el hombre trabaja para buscar alimento y no para dar sentido a su vida.

Como cuarta diferencia entre la teoría del valor de Hume y de Smith, para Smith el sacrificio que se realiza para lograr una compensación en forma monetaria parece poderse extender a todos los trabajadores y no ser subjetiva. Según la teoría de los dife- 
renciales salariales, será mayor el salario si es el trabajo es más difícil, más sucio, más deshonroso... y esas cualificaciones son semi-objetivas o dadas por la estructura social en la que se mueve el trabajador. Sin embargo, la idea de "coste" en el caso de Hume se hace más individual, y eso también implica un derecho de propiedad por lo trabajado.

Esta diferencia nos puede llevar a plantear una quinta distinción entre los dos autores. Si en el caso de Hume es sólo la oferta y la demanda lo que determina el precio, no debe existir un valor natural de los bienes y factores dado "en el ideal del valor" o en el largo plazo práctico. No existe, por tanto, ese precio tope que para Smith hacía que la escasez convirtiera en "bueno" el incremento de precios y señalase el momento en que se pudiera comenzar la producción sistemática del bien para conservar el recurso. Eso le daba a Smith la posibilidad de hablar de una demanda efectiva de los bienes que son capaces de pagar el precio natural, dentro del cual estaría la renta de la tierra.

\section{La figura del empresario}

\subsection{Diferentes teorías del empresario}

El concepto de valor de los bienes tiene una relación directa con la iniciativa/función empresarial por lo menos en dos sentidos. Si el valor depende del coste, una parte del coste consiste en el riesgo empresarial retribuido por el beneficio. El concepto de beneficio del empresario es la clave para definir su figura y sus funciones y el crecimiento y cambios en la economía en su conjunto ${ }^{90}$. Pero, además, el empresario es el que selecciona los bienes que el mercado crea, de manera que es el que, en última instancia, calcula el valor de los mismos, o bien en función de la utilidad del consumidor, o bien en función del coste de producción, a la espera de persuadir al consumidor de su utilidad. Así pues, se convierte en el lazo esencial entre valor y producción. Las teorías del empresario de los autores se basan, en definitiva, en sus diferentes teorías del valor y en su caracterización de la acción humana.

\subsection{Hume y el empresario como hombre activo}

Por ejemplo, para dibujar la figura del empresario en la teoría de Hume, podemos comparar su tratamiento de la actividad económica como acción satisfactoria con sus

90 Ver Santos (1997) y Valdaliso y López (2007). 
conclusiones en el libro II del Tratado Of curiosity or the love of truth. Como en el caso del trabajo, en este ensayo Hume muestra que el placer derivado del estudio no consiste en el logro de un conocimiento válido como tal, sino en la acción de la mente y el ejercicio del entendimiento. Pero esa empresa, para que sea gratificante, debe cumplir dos condiciones. Primero, debe ofrecer un reto genuino a nuestras capacidades. "Lo que es sencillo y obvio nunca es valorado" $"$. En segundo lugar, debe poseer alguna utilidad, que provee ese pequeño pero crucial margen de interés necesario para "fijar nuestra atención" en algún objetivo y evocar un esfuerzo organizado. Sin embargo, paradójicamente, aunque la actividad debe dirigirse hacia un objetivo valioso, el objetivo de la actividad es la actividad misma, que sirve como el verdadero fin de la pasión. Hume dice que el objetivo del conocimiento es semejante al de la caza, en que el placer consiste "en la acción de la mente y el cuerpo, el movimiento, la atención, la dificultad y la incertidumbre" ${ }^{\prime \prime 2}$.

Esta idea del cazador es una buena descripción de la figura del empresario humeano. El empresario necesita acción, es inquieto, no puede descansar largo tiempo sin caer en un estado de languidez ${ }^{93}$. La utilidad de los bienes que produce no es más que ese pequeño, pero crucial, margen de interés, para fijar su atención y evocar un esfuerzo organizado. El empresario no se mueve por una imagen del bien social que crea; sin embargo, tal vez considere insípida una empresa sin un supuesto valor social. Ese valor, en definitiva, es un fin instrumental para llevar a cabo el deseo de dar expresión a la inteligencia de un modo útil. Sin embargo, según Hume, aunque el empleo lucrativo disminuye el deseo de placer, como despierta el deseo del éxito en el logro, lleva a un amor a la ganancia y llegará un momento en que el empresario "no tendrá otro placer que el de ver cómo crece diariamente su fortuna"94. Finalmente, el hombre adquiere amor a esa actividad por imitación: "El comercio incrementa la industriosidad, al trasmitirla de un miembro del Estado a otro, y no dejando que ninguno se haga inútil”95.

\subsection{Smith, ¿empresario prudente o loco aventurero?}

Sin embargo, Smith es más crítico de la idea de empresario que Hume. Como en la teoría del valor, la figura del empresario Smithiana difiere de la descrita en la tradición de Cantillon - Say ${ }^{96}$. En la $R N$, no está clara la diferencia atribuida a Say entre

\footnotetext{
91 Hume (1964b), p. 224.

92 Hume (1964b), p. 226.

93 Por tanto su acción es en cierto modo reactiva.

94 Hume (1964c), p. 325.

95 Ibíd.

96 Como afirma Spengler (1975).
} 
el premio del empresario como organizador y el premio del capitalista. Smith conocía el trabajo de Cantillon y sin embargo, decidió presentar un decisor que enfrenta el riesgo como una rutina más ${ }^{97}$.

La figura del empresario sale en la $\mathrm{RN}$ en tres casos por lo menos: como el aventurero, que en el período de Smith era el mercader. Según Smith, los aventureros son aquellos que tienen excesiva confianza en su éxito y arriesgan su capital en las más difíciles empresas, no para anticipar la utilidad, si no para persuadir y convencer a través del lenguaje ${ }^{98}$. El empresario no es el "gran hombre" que prevé los placeres del público en contextos de incertidumbre. Es el "hombre blanco" que irrumpe entre los indios para convencerles de que las novedades de la civilización bien valen sus baratijas de oro.

El segundo tipo de empresario es el especulador (el projector), hacia los que en el tiempo de Smith ya existía una actitud hostil. Smith los trata con ironía o desprecio; divierten el público con sus "cuentos" de los beneficios inmensos que pueden hacer, y hacen proyectos caros e inciertos que llevan a la bancarrota a la mayoría de aquellos que se comprometen con ellos. La hostilidad a los especuladores no se debe a su cualidad planificadora, algo característico de la clase capitalista ${ }^{99}$. El problema de los especuladores es que son gente soberbia e imprudente, es decir, que no tiene en cuenta la imprevisibilidad del tiempo. El perjuicio que causa el especulador es mayor que el del aventurero porque esos planes o diseños de cuya oportunidad ha convencido a muchos hombres llevan a que éstos se arriesguen, pierdan su dinero, se reduzca el capital productivo y, sobre todo, la gente deje de tener confianza en el tráfico mercantil, lo que afecta negativamente en el largo plazo. El innovador está arriesgando el esfuerzo institucional acumulado, incluida la confianza en el futuro ${ }^{100}$.

Por último, Smith habla del hombre prudente que ahorra e invierte para obtener el beneficio ordinario en líneas de producción más o menos conocidas. Tiene la cualidad de la abstinencia y es el hombre del progreso, lento pero seguro, que se contenta con pequeñas acumulaciones. Realiza sus proyectos con suficiente información presente y con una relación entre beneficio esperado y riesgo aceptable, dado que sabe que sólo si ahorra podrá incrementar la cantidad de su capital de manera cons-

97 Según Schumpeter (1954), p. 555, Smith no tenía teoría del empresario. Sin embargo, Knight (1947) dice que Smith reconoce que el beneficio contiene un elemento que no es el interés del capital. Según Hollander (1973), p. 170, Smith formuló el concepto de beneficio como un premio a la incertidumbre de la renta ganada con la utilización del capital en el establecimiento de una empresa.

$98 \quad$ Smith (1994), p. 167.

99 Smith (1994), p. 342. Tuttle (1927) considera que para Smith organizar y dirigir el trabajo es el elemento determinante de la función con la que se asocia el beneficio.

100 Smith defendió el establecimiento de un máximo legal al tipo de interés sin el cual sólo podrían tomar préstamos los pródigos y especuladores. La relación con su visión de la figura de empresario es obvia: los fraudes o pérdidas en este campo no sólo afectan a las partes sino que somete al inversor a un riesgo moral bajo el sesgo de la información asimétrica. 
tante. La prudencia tiene importancia tanto en la economía de Smith, como en su ética y en el cuerpo político precisamente porque sin ella no habría autocontrol ${ }^{101}$.

De hecho, la única labor que el capitalista no puede delegar a un trabajador asalariado es el hecho de ahorrar e invertir su propio capital acumulado, de modo que esa es la función diferencial del empresario-capitalista. Por tanto, lo que incrementa la cantidad de capital no es la mayor inventiva ni el "hombre excepcional", sino "la habilidad, destreza y juicio con que habitualmente se realiza el trabajo"102.

Así, según Smith, el hecho de arriesgarse en nuevas formas de coordinar el trabajo, no puede incrementar la riqueza nacional. La innovación en este campo sólo podría ser una que hiciese más productivo el trabajo, pero la división del trabajo es una "innovación" que se produce de forma no premeditada, gradual, y no se debe forzar a ningún canal una cuota mayor de la que naturalmente fluiría hacia él espontáneamente. El riesgo empresarial que busca innovaciones sólo puede dar beneficios temporalmente, y en poco tiempo las otras empresas asumirán la innovación y reducirán con su competencia el margen de beneficio ${ }^{103}$. Smith pone más énfasis en el automatismo del mercado en restaurar el equilibrio que en la importancia de la función innovativa de los empresarios. Como en su teoría del valor, el valor del empresario es lo que le cuesta a la sociedad el capital acumulado que pone en riesgo a la hora de montar una empresa.

\subsection{Bentham, una Defensa del empresario talentoso}

Bentham, sin embargo, defiende a los aventureros y especuladores en su Defence of usury, volviendo a la tradición francesa de Cantillon - Say, basada en la oferta ${ }^{104}$. Bentham reprocha a Smith el haber infraestimado el papel de esos "hombres de talento" que, a través de su invención e imaginación, son responsables del progreso y de la riqueza de las naciones, dado que encuentran nuevos canales de comercio -

101 Sobre la prudencia en la economía de Smith ver Fleischacker (2004), en la ética ver Griswold (1999), pp. 202-9 y en el cuerpo político ver Evensky (2005). Sobre el autocontrol en Smith, ver Montes (2004). Sin embargo, no olvidemos que la prudencia, por ser habitual, no es la virtud más admirable según Smith, si no el autocontrol dirigido a la justicia.

Smith (1994), p. 27. Como dice Khan (1954), Smith da importancia al papel del capital y no es la industria sino la parsimonia o la abstinencia la causa de la acumulación. Pero una vez acumulado el capital, el dinero hace dinero casi de manera inmediata. En base a esa idea, Smith pudo crear una teoría de los estadios en que el desarrollo comienza en la agricultura de pequeña escala.

103 Smith (1994), p. 173.

104 Hébert y Link (2006). También Hébert y Link (1988), pp. 50-54, recogen la obra de Bentham sobre el empresario y destacan que sus vínculos con la tradición intelectual francesa eran más fuertes que los de sus contemporáneos, ver Santos (1997), p.35. La tradición francesa es analizada en Menudo y O’Kean (2006). 
abren caminos hacia el futuro. Bentham nos habla de la productividad incrementada por nuevas ordenaciones de los medios de producción, especialmente en las manufacturas. La innovación es la fuerza que mueve el desarrollo porque "lo que es ahora institución, una vez fue innovación"105. Como en el Panopticon, la cárcel modelo que proyectó Bentham, la innovación administrativa genera incentivos económicos ${ }^{106}$.

Bentham se queja de que Smith relacione a pródigos y especuladores. Los segundos se caracterizan por separarse de los modelos rutinarios de comportamiento, sobresalir de la masa, con lo que son una élite restringida que requieren valor y genio (se atisba en Bentham una concepción aristocrática que desprecia a la gente común). Cita dos casos en que es necesario sólo el coraje, no el genio: la apertura de un nuevo mercado y la búsqueda de una fuente nueva de oferta ${ }^{107}$. Bentham quería que Smith revisara sus opiniones sobre la función llevada a cabo por el hombre prudente en su sistema, que, recuerda Bentham, no se embarca en proyectos nuevos. Sin embargo, Smith no cambió su teoría ${ }^{108}$.

Según la teoría Smithiana podríamos plantear varias respuestas a la crítica de Bentham.

En primer lugar, en la actividad empresarial, Bentham introduce un mesianismo semejante al que introduce con el Estado. Dado que el mercado o los individuos no pueden afrontar el proceso de crecimiento, es necesario que nos salve un Mesías, con caracteres semi-divinos. Smith, contra Bentham, está suponiendo la igualdad entre los hombres, en base a la tabla rasa lockiana: no podemos suponer que los aventureros tengan un conocimiento superior sobre el futuro que otro tipo de personas. Si Bentham muestra una actitud aristocrática, Smith, sin embargo, muestra una cierta preferencia por las condiciones medias y bajas de la sociedad, y en particular por las medias, la clase ahorradora según $\mathrm{Smith}^{109}$. En vez de ser el empresario el que produce el crecimiento económico, es la división del trabajo la que produce al empresario, como en cualquier otra actividad. El inventor es un trabajador que, por estar continuamente utilizando una máquina determinada, imagina un medio nuevo para reducir su esfuerzo

\footnotetext{
105 Stark (1952b), p. 355.

106 Hébert y Link (2006), p. 591.

107 Cuando añadimos los otros dos determinantes de la innovación - la producción de un nuevo bien y la introducción de un nuevo método de producción -, tenemos 4 de las 5 combinaciones nuevas que cita Schumpeter en "Theory of economic development" (pero éste sólo hace una referencia breve a Bentham en Schumpeter (1949), p. 64, ver Heberton (1949), aunque consideraba que Bentham había sido quien con más claridad percibió la naturaleza de la función empresarial, Schumpeter (1966).

108 Pesciarelli (1989) destaca el hecho de que Smith tenga como "hombre ideal" al hombre corriente y frugal mientras que Bentham - y Schumpeter - entronizan al individuo excepcional y aventurero. La visión de Smith contrasta con la de Schumpeter, que dirá que el empresario "camina hacia el éxito sobre el cordel de deudas".

109 Smith (1997), p. 132 y Smith (1997), p. 140-1. La gente de clase media, que no han nacido ricos pero que poseen un pequeño capital, lo ahorran e invierten. Como dice Santos (1997), podemos relacionar esta explicación con la teoría del consumo de Milton Friedman, basada en el concepto de "renta permanente".
} 
y mejorar la máquina110. “No hay nada tan misterioso en las invenciones de las máquinas como para que cualquiera no hubiera podido haber sido su inventor"111. El único medio de promover las invenciones es creando un derecho de propiedad intelectual por un tiempo prudencial, sin el cual se desestimularían totalmente ${ }^{112}$.

Pero, en segundo lugar, los aventureros y especuladores son un "tipo" de gente que, por sus hábitos, tiene algunas características diferenciales respecto a la mayoría de los hombres, que confían en el futuro aunque lo temen. El aventurero y especulador se diferencian en aquello en lo que se han especializado: arriesgarse. Su carácter, incluso, se habrá acostumbrado a ello y habrán perdido el resorte de la prudencia ${ }^{113}$. Pero éstos están afectando a la psicología de la gente común, dada la influencia de la imitación en las costumbres empresariales y en la prodigalidad, lo que, de facto, lleva a un incremento del tipo de interés ${ }^{114}$.

En tercer lugar, Bentham dice que el empresario introduce una mejora, se adentra en senderos desconocidos o bien en la producción de un nuevo bien adaptado al uso humano o en el mejoramiento de su calidad y disminución su gasto ${ }^{115}$. "El término projector... se da a todas las personas que, en el cultivo de esas artes que han sido llamadas útiles, dirigen sus esfuerzos a cualquiera de esos departamentos en que su utilidad parece más indudable"116. Su función, por tanto, es captar la utilidad del bien final anticipadamente. Esta diferencia entre ambos autores es crucial, una confusión que se ha reproducido en la historia del pensamiento económico y que se basa en la misma confusión de la teoría del valor. Para Smith, el empresario es una figura que puede ser positiva cuando promueve un crecimiento continuado; para Bentham es positiva cuando rompe las rutinas empresariales y, es de suponer, investiga sobre los gustos de los consumidores que, si adquieren su producto, están saciando un deseo anterior a la compra, aunque sea subconsciente ${ }^{117}$. Puesto que para Smith el empresario no realiza la labor de búsqueda de la felicidad del consumidor, el empresario usa un capital para crear en muchas ocasiones "necesidades", no felicidades. Según Bentham, los nuevos negocios siempre son más arriesgados, pero toda rutina alguna vez fue novedad; lógicamente, "una" de las novedades que tuvo éxito, al modo del darwinismo.

Smith (1978), p. 570, "Early Draft of Part of the Wealth of Nations", párr. 18.

Smith (1978), p. 346, LJ (A): VI: 4. Sobre la actividad inventiva y la división del trabajo ver Rosenberg (1965) y (1976); Ippolito (1977); y Groenewegen (1977).

Smith (1978), p. 472, LJ (B): 175.

Sin embargo, para Bentham el riesgo es un "placer" anticipado y los placeres son más intensos cuanto más inciertos, Dube (1991), p. 97 (contra lo que afirma Hume).

Una idea que Smith toma de Hume y que en cierto modo se contraría con la universalidad de la tendencia al trabajo y ahorro típicos de la teoría de Smith. Ver Smith (1994), p. 604; Smith (1994), p. 149.

Aquí, Bentham usa cursivas para la palabra "mejora" porque diferencia entre mejora (un nuevo método de combinar recursos para propósitos productivos) e invención (progreso científico).

Stark (1952a), p. 170, Defence of Usury.

Stark (1954), p. 425. 


\section{Conclusión}

Hemos visto cómo influye la concepción del tiempo (ligada al pasado, al futuro o al presente) y la definición del agente económico (un hombre ético y prudente o un hombre estético o buscador de placeres) en la teoría del valor económico, así como en la teoría del empresario, en tres distintos autores, Smith, Bentham y Hume. La concepción presentista de Smith buscaba un crecimiento económico basado en la continuidad, y su teoría del valor-coste se basaba en la idea del darse cuenta de una realidad ulterior, más allá del capricho individual. Sin embargo, la teoría de Bentham es subjetivista e individualista, y precursora del marginalismo, precisamente porque concibe la imagen de un mundo perfecto como una suma de utilidades individuales que, además, se definen como una expectativa futura. Hume, por último, tiene una concepción de utilidad basada en el hábito y es la resistencia al miedo y a un sentimiento de languidez romántico lo que nos mueve. Para luchar contra este sentimiento, el hombre intenta ser activo en lo individual, pero conservador en lo social.

La figura del empresario es muy distinta en los tres autores. Para Hume el empresario se asemeja al cazador que necesita acción, que no puede descansar largo tiempo sin caer un estado de languidez. Para Smith, el empresario es el aventurero o especulador que, sólo por querer destacar, es capaz de poner en peligro el capital acumulado por toda una sociedad. Pero es también el administrador prudente que quiere darse cuenta de la consecuencia de sus acciones. Bentham, por último nos habla del "hombre de talento" que abre el futuro a la novedad a través de su invención e imaginación, y que provoca un crecimiento Schumpeteriano, una destrucción creadora.

El hecho de que existan los tres tipos humanos hace que las tres sean teorías, en parte, explicativas. Sin embargo, es cierto que lo estético, al ser un estado "del momento", parece una base menos sólida para crear una ciencia. Efectivamente, la ciencia se construye con el recuerdo, no con el olvido; con la realidad presente, no con la imaginación. Una teoría basada en el hombre estético necesariamente está abocada a explicar estados paralelos e irregulares, en cierto modo excepcionales ${ }^{118}$. Toda explicación pasa por un equilibrio, y la no existencia de equilibrio es la no explicación ${ }^{119}$.

118 De hecho, Hume consideraba que la indeterminación de la conducta humana hace imposible cualquier predicción política, ver Stewart (1977), pp. 172-173.

119 Urrutia (1983), p. 148, dice que es la infinitud del conjunto la que facilita la existencia del equilibrio. Toda explicación es atemporal o puede reconstruirse como atemporal sin pérdida de información. 


\section{Bibliografía}

ÁRDAL, Pall S. (1966): Passion and Value in Hume's Treatise, Edinburgh, University of Edinburgh Press.

BENTHAM, Jeremy (1981): Tratados de legislación civil y penal, Madrid, Editora Nacional.

BLACK, R. D. Collinson, (1988): "Bentham and the Political Economists of the Nineteenth Century", The Bentham Newsletter: 12, pp- 24-36.

BLAUG, Mark (1959): "Welfare indices in the Wealth of Nations", The Southern Economic Journal, 26, pp. 150-3.

BONNER, John (1995): Economic Efficiency and Social Justice: The Development of Utilitarian Ideas in Economics from Bentham to Edgeworth, Aldershot, Edward Elgar.

CABRILLO, Francisco (1991): Lecturas de Economía Politica, Madrid, Minerva Ediciones.

CANTILLON, Richard, (1950 [1755]): Ensayo sobre la naturaleza del comercio en general, México, FCE.

CASTÁN, José (1987): Derecho civil español, común y foral. Vol. II, Madrid, Reus.

DAS GUPTA, Ajit Kumar (1960): “Adam Smith on value", Indian Economic Review, 5, pp. 105-15.

DAVIDSON, Donald, (1976): "Hume's Cognitive Theory of Pride", The Journal of Philosophy, 73, 19, pp. 744-757.

DIAYE, Marc-Arthur y LAPIDUS, André (2005): “A Humean Theory of Choice of which rationality may be one consequence", European Journal of History of Economic Thought, 12, 1, pp. 89-101.

DUBE, Allison (1991): The Theme of Acquisitiveness in Bentham's political thought, New York, Garland publishing.

EKELUND, Robert B. y HÉBERT, Robert F. (1992): Historia de la teoría económica y de su método, México, McGraw-Hill.

EVENSKY, Jerry (2005): Adam Smith's Moral Philosophy: A Historical and Contemporary Perspective on Markets, Law, Ethics, and Culture, New York, Cambridge University Press.

FLEISCHACKER, Samuel (2004): On Adam Smith's Wealth of nations: A philosophical companion, Princeton, Princeton University Press.

GARRETT, Don (1997): Cognition and Commitment in Hume's Philosophy, Oxford, Oxford University Press.

GRISWOLD, Jr, Charles (1999): Adam Smith and the Virtues of Enlightenment, Cambridge, Cambridge University Press.

GROENEWEGEN, Peter (1977): "Adam Smith and the Division of Labour: A Bicentenary Estimate", Australian Economic Papers, pp. 161-74.

HAAKONSSEN, Knud (1995): The Science of a Legislator, Cambridge, Cambridge University Press.

HARRIS, Marvin (1983): Introducción a la antropología general, Madrid, Alianza. 
HÉBERT, Robert. F. and LINK Albert N. (1988): The Entrepreneur. Mainstream Views and Radical Critics ( $2^{\mathrm{a}}$ edición), Nueva York, Praeger.

-(2006): "The Entrepreneur as innovator", Journal of Technology Transfer, 31, pp. 589-597.

HEBERTON, Evans Jr, G. (1949): “The entrepreneur and economic theory, a historical and analytical approach" The American Economic Review, Papers and Proceedings, XXXIX, pp. 337-38.

HENDERSON, John P. (1954): "The Macro and Micro Aspects of the Wealth of Nations", en The Southern Economic Journal, 21, pp. 25-35.

HOLLANDER, Samuel (1973): The economics of Adam Smith, London, Heinemann Educational Books.

HUME, David (1964 a): The Philosophical Works, Vol. I, Londres, Scientia Verlag.

—(1964 b): The Philosophical Works, Vol. II, Londres, Scientia Verlag.

—(1964 c): The Philosophical works. Essays Moral, Political and Literary, Vol. I, Londres, Scientia Verlag Aalen.

-(1986): Historia de Inglaterra bajo la casa de Tudor (selección), 2 Vols., Barcelona, Orbis.

HUTCHISON, Terence W. (1976): “The Bicentenary of Adam Smith", Economic Journal: 86: pp. 481-92.

IPPOLITO, Richard A. (1977): “The Division of Labour in the Firm", Economic Inquiry, 15, pp. 469-92.

JEVONS, William Stanley (1998): La Teoría de la Economía Política, Madrid, Pirámide [1871].

KAUDER, Emil (1953): "Genesis of the Marginal Utility Theory", Economic Journal, 63, 251, pp. 638-50.

KEYNES, John Maynard (1925): "Alfred Marshall", Memorials of Alfred Marshall, Londres, ed. A. C. Pigou.

KHAN, Mustaq S. (1954): "Adam Smith`s Theory of Economic Development (in Relation to underdeveloped Economies)", Indian Journal of Economics, Vol. 34, abril, pp. 337-42.

KIEERKEGARD, Soren (1965): Obras y papeles de S. Kierkegaard, Madrid, Guadarrama.

KNIGHT, Frank H. (1947): Riesgo, Incertidumbre y Beneficio, Madrid, Aguilar.

LAPIDUS, André y SIGOT, Nathalie (2000): “Individual utility in a context of asymmetric sensitivity to pleasure and pain: an interpretation of Bentham's felicific calculus" European Journal for the History of Economic Thought, 7, 1, pp. 45-78.

LEVY, David M. (1999): "Adam Smith`s Katallactic model of gambling: approbation from the spectator", Journal of the History of Economic Thought, 21, 1, pp. 81-91.

MARSHALL, Mike G. (1998): "Scottish Economic Thought and the High Wage Economy: Hume, Smith and McCulloch on Wages and Work Motivation", Scottish Journal of Political Economy, 45, 3, pp. 309-328.

MENUDO, José María y O'KEAN, José María, (2006): “The French Tradition: an Alternative Theoretical Framework", Working papers series, WP ECON 06.24, Department of Economics, UPO. 
MILL, John Stuart (1978): Principios de Economía Política, México, FCE.

MITCHELL, Wesley C. (1918): “Bentham's Felicific Calculus”, Political Science Quarterly, 33, 2, pp. 161-183.

MONTES, Leonidas (2004): Adam Smith in Context: A Critical Reassessment of Some Central Components of His Thought, New York, Palgrave Macmillan.

MURPHY, Antoine E. (ed.) (1984): "Francis Ysidro Edgeworth," Economists and the Irish Economy. From the $18^{\text {th }}$ century to the present, Dublin, Irish Academic.

O’BRIEN, Denis P. (1989): Los economistas clásicos, Madrid, Alianza.

PESCIARELLI, Enzo (1989): "Smith, Bentham and the development of contrasting ideas on entrepreneurship", History of Political Economy, 21, 3, pp. 521-36.

POWNALL (1776): “A letter from Governor Pownall to Adam Smith”, Apéndice A en Mossner, Ernest Campbell y Ross, Ian Simpson (eds.), The Correspondence of Adam Smith, 1977, Oxford, Clarendon Press.

RICARDO, David (1966): The works and correspondence of David Ricardo, Vol.2, Cambridge, The University Press for the Royal Economic Society.

ROBBINS, C. Lionel (1953): The Theory of Economic Policy in English Classical Political Economy, Londres, MacMillan.

RONCAGLIA, Alessandro (1997): “Reseña del libro de John Bonner, Economic Efficiency and Social Justice", Journal of the History of Economic Thought, 19, 2, p. 319.

ROSENBERG, Nathan (1965): "Adam Smith on the Division of Labour: Two Views or One", Economica, 32, pp. 127-39.

-(1976): "Another Advantage of the Division of Labour", Journal of Political Economy, 84, 4, pp. 861-8.

ROSS, Ian Simpson (1995): The Life of Adam Smith, Oxford, Clarendon Press.

SANTOS, Manuel (1997): Los economistas y la empresa. Empresa y empresario en la historia del pensamiento económico, Madrid, Alianza.

SCHUMPETER, Joseph A. (1954): History of Economic Analysis, Oxford, OUP.

-(1949): Change and the entrepreneur, Cambridge, Harvard University.

-(1966): "La teoría económica y la historia empresarial" (1949), en Ensayos, Barcelona, Oikos-Tau, pp. 255-272.

SCHWARTZ, Pedro (1996): “ ¿Importan los hechos para los juicios morales? Una defensa contra la navaja de Hume basada en la noción de coste de oportunidad", Télos, V, 2, pp. 87-113.

SMITH, Adam (1976): An Inquiry into the Nature and Causes of the Wealth of Nations, The Glasgow Edition of the Works and Correspondence of Adam Smith, Vol. II, Volume I and II, Indianapolis, Oxford University Press (WN).

-(1978): Lectures on Jurisprudence, The Glasgow Edition of the Works and Correspondence of Adam Smith. Vol. V, Oxford, Oxford University Press (LJ (A) de 1762-3; LJ (B) de 1766).

-(1980): Essays on Philosophical Subjects, The Glasgow Edition of the Works and Correspondence of Adam Smith. Vol. III, Indianapolis, Oxford University Press [1795]: (EPS). 
-(1985): Lectures on Rhetoric and Belles Lettres, Indianapolis, Liberty Fund.

- (1987): The Correspondence of Adam Smith, The Glasgow Edition of the Works and

Correspondence of Adam Smith, Vol. VI, Indianapolis, OUP.

-(1994): La riqueza de las Naciones, Madrid, Alianza [1776]: (RN).

-(1997): La Teoría de los Sentimientos Morales, Madrid, Alianza (TSM) [1759].

SPENGLER, Joseph J. (1975): “Adam Smith and society`s decision-makers", Essays on Adam Smith, Skinner A. S. y Wilson T. (eds.), Oxford, Oxford Clarendon Press, pp. 397-400.

STARK, Werner (1952a): Jeremy Bentham`s Economic Writings, Vol. I, Londres, The Royal Economic Society.

-(1952b): Jeremy Bentham`s Economic Writings, Vol. II, Londres, The Royal Economic Society.

-(1954): Jeremy Bentham`s Economic Writings, Vol. III, Londres, The Royal Economic Society.

STEWART, John, B. (1977): The Moral and Political Philosophy of David Hume, Connecticut, Grenwood Press Publishers.

SUGDEN, Robert (1991): "Rational choice: a survey of contributions from economics and philosophy", Economic Journal, 101, pp. 751-785.

TRINCADO, Estrella (2003a): Crítica a la doctrina de la Utilidad y Revisión de las teorías de Hume, Smith y Bentham, E-PrintsUCM, Madrid.

-(2003b): "Adam Smith: crítico del utilitarismo", Télos. Revista Iberoamericana de Estudios Utilitaristas, XII, 1, pp. 43-62.

-(2004): "Bentham. Precursor de los Austríacos", Procesos de Mercado. Revista Europea de Economía Política, 2, 2, pp. 119-49.

-(2005): "Utility, Money and transaction costs: Authoritarian vs libertarian monetary policies", History of Economic Ideas, XIII, 1, pp. 57-77.

-(2006): "Adam Smith criticism of the doctrine of utility: a theory of the Creative Present", en Montes, Leonidas y Schliesser, Eric (eds.), New Voices on Adam Smith, New York and London, Routledge, pp. 313-327.

-(2008): Estudio preliminar Ensayos Morales y Literarios de David Hume, Madrid, Tecnos.

TUTTLE, Charles A. (1927): "The entrepreneur function in economic literature”, Journal of Political Economy, Agosto, pp. 504-5.

URRUTIA, Juan (1983): Economía Neoclásica, Madrid, Pirámide.

VALDALISO, Jesús María y LÓPEZ, Santiago (2007): Historia económica de la empresa, Barcelona, Editorial Crítica.

VIVENZA, Gloria (2001): Adam Smith and Classics. The Classical Heritage in Adam Smith's thought, Oxford, Oxford University Press.

YOUNG, Jeffrey T. (1995): "Natural Jurisprudence and the Theory of Value in Adam Smith", History of Political Economy, 27, 4, pp. 755-773. 